\title{
ACTH-induced recovery of extinguished avoidance responding
}

\author{
RICK RIGHARDSON, DAVID C. RICCIO, and LISA DEVINE \\ Kent State University, Kent, Ohio
}

\begin{abstract}
In addition to prolonging the resistance to extinction of aversively motivated behavior, administration of ACTH at testing has been shown to alleviate retention deficits associated with several types of paradigms (e.g., retrograde amnesia, Kamin effect). To determine whether comparable recovery could be induced by ACTH with respect to a previously extinguished avoidance response, four experiments using rats were conducted. In each, decrements in avoidance responding produced by extinction were alleviated by exogenous ACTH. For three reasons, the observed effects of ACTH on rats' avoidance behavior were judged to be on memory processes rather than simply an alteration in motor behavior. First, pretest administration of ACTH was effective in alleviating performance deficits after extinction in both active (Experiment 1) and passive (Experiments 2-4) avoidance tasks. Second, administration of ACTH had no effect on the behavior of shocked, but untrained, subjects (Experiment 3). Finally, the ACTH-induced recovery was relatively durable in that it persisted for at least $24 \mathrm{~h}$ (Experiments 3-4). This durability of the ACTH-induced recovery of avoidance was unexpected in terms of an interpretation emphasizing the state-dependent nature of the present paradigm. The data extend previous findings and are discussed in relation to other research on memory recovery.
\end{abstract}

In recent years, many investigations on the effects of exogenously administered adrenocorticotropic hormone (ACTH), or related peptide fragments, on learned behaviors have been reported. In an extensive series of investigations, deWied and his colleagues (Bohus \& deWied, 1966, 1981; deWied, 1966) have examined the influence of exogenously administered ACTH, or a related peptide fragment, on the rate by which an avoidance response extinguishes. Typically, it has been found that animals administered ACTH prior to the extinction session are more resistant to extinction than are subjects administered saline. That is, subjects given ACTH prior to an extinction session continue to perform the conditioned response longer than controls.

Other investigators have examined the effects of ACTH on some process other than rate of extinction. For example, exogenous administration of $\mathrm{ACTH}$, or a related peptide fragment, has been found to be an effective method of alleviating retention deficits produced by a wide variety of experimental treatments. Rigter, Van Riezen, and deWied (1974) demonstrated that $\mathrm{CO}_{2}$-induced retrograde amnesia (RA) for a passive avoidance task could be attenuated by injecting $\mathrm{ACTH}_{4-10}$ shortly prior to the retention test. Similarly, Mactutus, Smith, and Riccio (1980) demonstrated the alleviation of hypothermia-induced RA

This research was supported by Grant MH37535 to D.C.R. Reprints may be obtained from either of the first two authors. Experiments 1 and 2 were presented at the Eastern Psychological Association meeting, Philadelphia, April 1983; Experiments 3 and 4 were presented at the Midwestern Psychological Association meeting, Chicago, May 1984. The assistance of Kim Nagy, Emika Okonkwo, and John Steele are gratefully acknowledged. The authors' mailing address is: Department of Psychology, Kent State University, Kent, OH 44242. by pretest injections of ACTH. These later investigators also found that injecting ACTH shortly prior to a cuing exposure (a brief nonreinforced exposure to the originally established fear cues) extended the duration of memory recovery. Typically, ACTH administration produces a transient recovery (several hours or less) of the amnestic memory (Mactutus, Smith, \& Riccio, 1980, Experiment 2), but subjects that had been injected with ACTH shortly prior to a cuing treatment exhibited recovery of the amnestic memory for 7 (but not 14) days (Mactutus, Smith, \& Riccio, 1980, Experiment 3).

The more durable memory recovery produced by the cue-ACTH pairing procedure obtained in Mactutus, Smith, and Riccio (1980) is similar to a finding reported by Haroutunian and Riccio (1979) with respect to the ontogeny of retention. In examining the more rapid rate of forgetting typically found for young as compared with adult rats (i.e., infantile amnesia), Haroutunian and Riccio observed that reexposure to the originally established fear cues in combination with an injection of ACTH midway through the retention interval was more effective in alleviating infantile amnesia than either of these two treatments administered separately.

Another demonstration of the effectiveness of ACTH in alleviating a retention deficit comes from the work of Klein (1972) on the Kamin effect (Kamin, 1968, 1969). Kamin and others (Kamin, 1968; Klein \& Spear, 1970) showed that subjects trained on an active avoidance task and then tested after an intermediate retention interval (1$6 \mathrm{~h})$ perform more poorly than subjects tested either immediately or $24 \mathrm{~h}$ after training. However, Klein (1972) demonstrated that subjects tested after an intermediate retention interval did not show the usual retention loss 
if they were injected with ACTH shortly prior to the test session. Apparently, ACTH facilitated retrieval of the aversive memory at the intermediate retention interval.

An assumption underlying much of this research on ACTH-induced memory recovery was that exogenously administered ACTH would be effective in alleviating retention deficits because endogenous ACTH was a component of the training memory. That is, with the aversively motivated conditioning tasks employed in these studies, activation of the pituitary-adrenal system and release of ACTH occur at the time of training. This hormonal state, and correlated physiological changes, would thus be encoded or represented in the memory of the training episode. Injecting ACTH shortly prior to the test session increases the similarity between training and testing and enhances the probability of retrieving the training memory (cf. Spear 1973, 1978). If this interpretation is correct, then recovery of an extinguished aversively motivated response might be achieved by administering ACTH shortly prior to test.

Although deficits produced by an extinction treatment are not typically thought of as retention phenomena, both stimulus sampling theory (Estes, 1955) and empirical data suggest some commonalities between performance decrements resulting from manipulations involving extinction or retention loss. For example, noncontingent footshock (NCFS) is often used to alleviate retention deficits produced by experimentally induced retrograde amnesia (Mactutus, Ferek, \& Riccio, 1980; Miller \& Springer, 1972). Similarly, Rescorla and Heth (1975) demonstrated that NCFS prior to testing was effective in producing substantial recovery of an extinguished conditioned emotional response. Regardless of whether performance deficits produced by extinction of aversive conditioning are viewed as retention losses or not, pretest injections of ACTH would be expected to increase the similarity between training and testing and thus enhance the probability that the training memory would be retrieved.

Thus, in the present study, the effectiveness of ACTH in producing recovery of a previously extinguished avoidance response was examined. We asked whether subjects that had been trained to make an avoidance response, and then had that response extinguished, would show improved retention at a later test when given ACTH prior to the test session. Unlike the work by deWied on ACTH and extinction (cf. Bohus \& deWied, 1981), the focus of the current study was not on the influence of exogenously administered ACTH on the rate of extinction, but rather on the effectiveness of exogenously administered ACTH in inducing recovery of an already extinguished avoidance response. This concern grows out of our more general interest in such manipulations as noncontingent footshock or hormone administration which facilitate memory retrieval in other paradigms.

\section{EXPERIMENT 1}

The aim of this experiment was to determine whether ACTH administration would increase the likelihood, or vigor, of a one-way active avoidance response that had undergone extinction. Initial training, extinction, and test sessions occurred on separate days. Shortly prior to testing, some subjects received one of two doses of ACTH. Other subjects received saline as a control for the effects of injection stress and to provide an assessment of baseline response levels, as some degree of spontaneous recovery would be expected following the $24 \mathrm{~h}$ interval separating extinction and test.

\section{Method}

Subjects. Fifty adult male rats (ranging in age from 111 to 243 days), purchased from the Holtzman Company, served as subjects. The subjects had been used in previous experiments. All had been trained earlier to passively avoid the black compartment of a black-white shuttlebox. In addition, the subjects had also been exposed to either hypothermia, an underwater T-maze problem, or consumption of a maltose solution These latter three experiences were randomly distributed across the treat ment conditions of this experiment. A minimum of 3 weeks separated use of subjects in this experiment from any previous treatment. The subjects were housed individually in hanging wire-mesh cages and maintained on a 15-/9-h light-dark cycle throughout the experiment. Food and water were available ad lib.

Apparatus. A $45.5 \times 20.5 \times 19.7 \mathrm{~cm}$ shuttlebox, divided by a clear Plexiglas partition into two equal-sized chambers, was used. The two end walls were of aluminum and the side walls, as well as the top, were of clear Plexiglas. A $7.5 \times 7.5 \mathrm{~cm}$ guillotine doorway separated the two compartments of the shuttlebox. The floor consisted of .3-cm grids spaced $1 \mathrm{~cm}$ apart. The floor was mounted in such a way that subjects' movement from one compartment to the other depressed a microswitch that was connected to a timer and printout counter. This allowed the recording of the subjects' latency on each trial (to the nearest .1 sec).

Procedures. An unsignaled one-way active avoidance procedure was used. Avoidance training consisted of placing a subject in one compartment (the shock side) of the apparatus, facing the open door. If the subject had not crossed into the other compartment (the safe side) within $5 \mathrm{sec}$, a 200-V shock was administered until the subject emitted the cross through response. A 15-sec intertrial interval (ITI), in which the subject was confined in the safe compartment, separated each trial. The subjects were trained until they had made five consecutive avoidances (i.e., responded in less than $5 \mathrm{sec}$ ). All subjects received 2 days of avoidance training.

Extinction trials were begun on Day 3 and were conducted the same as training trials, with the exception that responses greater than $5 \mathrm{sec}$ did not result in shock. On these "nonavoidance" trials, after the initial 5-sec interval, the door separating the two chambers was closed and the subject was placed on the safe side for the 15-sec ITI by the experimenter. The subjects received extinction trials until two consecutive response latencies of greater than $5 \mathrm{sec}$ had been emitted or until 50 extinction trials had been given. If a subject had not reached the extinction criterion of two consecutive "nonavoidances" by the end of 50 trials, additional extinction trials were given on the following day. On this 2nd day of extinction (if it was necessary), subjects were again given extinction trials until two consecutive "nonavoidances"' had been emitted or until 50 additional trials had been given. Subjects $(\mathbf{N}=9)$ that did not reach the extinction criterion by the end of the 2 nd day of extinction were discarded from the experiment. For the remaining subjects $(N=41)$, the retention test for the avoidance response occurred $24 \mathrm{~b}$ after the subject had reached the extinction criterion.

The subjects were randomly assigned to one of three different treatment conditions. Shortly prior to the retention test (10-15 $\mathrm{min})$, the subjects were injected subcutaneously with $40 \mathrm{IU}$ ACTH (Acthar gel, Armour Pharmaceutical), 80 IU ACTH, ${ }^{1}$ or 1 cc physiological saline. Subjects given saline served to control for any effects of the injection per se and any spontaneous recovery of the avoidance response that might have occurred overnight. Test trials were identical to extinction trials and were continued until a subject had made three consecutive "nonavoidances" or until 60 test trials had been given. A latency score of $5 \mathrm{sec}$ was assigned for any trial on which a "nonavoidance" occurred. 


\section{Results}

Training. Table 1 presents the median number of trials taken to reach criterion, and the median latency on the last five training trials for all three groups on both days of training. Visual inspection of these data suggested, and statistical analyses confirmed, that there were no significant differences on Day 1 or Day 2 with either measure. Separate Kruskal-Wallis ANOVAs demonstrated that subjects in the three treatment conditions required about the same number of trials to reach the training criterion $(\mathrm{H}$ $=2.00$ for Day $1 ; \mathrm{H}=2.35$ for Day 2 ; both $\mathrm{p}>.10$ ), and had equivalent average latencies on the last five training trials $(\mathrm{H}=.06$ for Day $1 ; \mathrm{H}=1.19$ for Day 2; both $\mathrm{p}>.10$ ).

Extinction. A Kruskal-Wallis ANOVA indicated that the number of trials taken on Day 1 of extinction did not differ across the three treatment conditions $(\mathrm{H}=2.10$, $p>.10)$. The median number of extinction trials on Day 1 for the saline, low-ACTH, and high-ACTH groups were 8,45 , and 23 , respectively. Although the low-ACTH group appears to have required more trials on Day 1 of extinction, this was not the case. All three groups were bimodal to some extent, and the differences in median scores result from a group's having one or two more extreme scores.

Further analysis (chi-square test of proportionality) on the proportion of subjects in each group requiring additional extinction trials on the 2nd day of extinction also proved to not be significant $\left[\chi^{2}(2)=1.31, p>.10\right]$. There were three subjects in the saline control group, five in the low-ACTH group, and three in the high-ACTH group that received extinction trials on Day 2 of extinction. All of the analyses on acquisition and extinction data demonstrate that the subjects assigned to the different treatment conditions did not differ prior to test. That is, faster or more persistent responders did not get assigned, by chance, to one of the treatment conditions.

Test. Figures 1 and 2 present the number of trials taken to reach the test criterion (three consecutive responses $>$ $5 \mathrm{sec}$; ceiling of 60 trials) and the median latency on the first five test trials, respectively. Although overall analyses of the data were not significant $(\mathrm{H}=4.96$ for latency on first five trials, $\mathrm{p}>.05 ; \mathrm{H}=4.33$ for trials to criterion, $p>.10$ ), given the a priori interest in the effect of ACTH on recovery of an extinguished avoidance response and the consistent pattern of the data, pairwise

Table 1

Acquisition Data from 2 Days of Training for Subjects in Experiment 1

\begin{tabular}{|c|c|c|c|c|c|}
\hline \multicolumn{3}{|c|}{ Day 1} & \multicolumn{3}{|c|}{ Day 2} \\
\hline Sal & $\begin{array}{c}\text { Low } \\
\text { ACTH }\end{array}$ & $\begin{array}{l}\text { High } \\
\text { ACTH }\end{array}$ & Sal & $\begin{array}{c}\text { Low } \\
\text { ACTH }\end{array}$ & $\begin{array}{c}\text { High } \\
\text { ACTH }\end{array}$ \\
\hline \multicolumn{6}{|c|}{ Trials to Criterion } \\
\hline 9.5 & 12 & 11.5 & 9.5 & 7 & 7.5 \\
\hline \multicolumn{6}{|c|}{ Latency: Last Five Training Trials } \\
\hline 1.39 & 1.4 & 1.69 & 1.19 & 1.06 & 1.48 \\
\hline
\end{tabular}

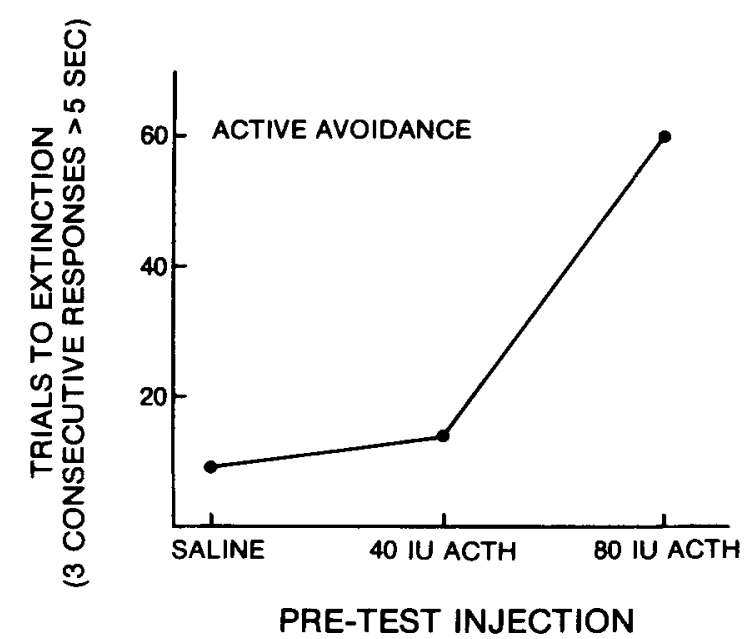

Figure 1. Median total trials taken to emit three consecutive "nonavoidances" in Experiment 1. All animals had been extinguished previously and received an injection of saline or one of two doses of ACTH prior to test.

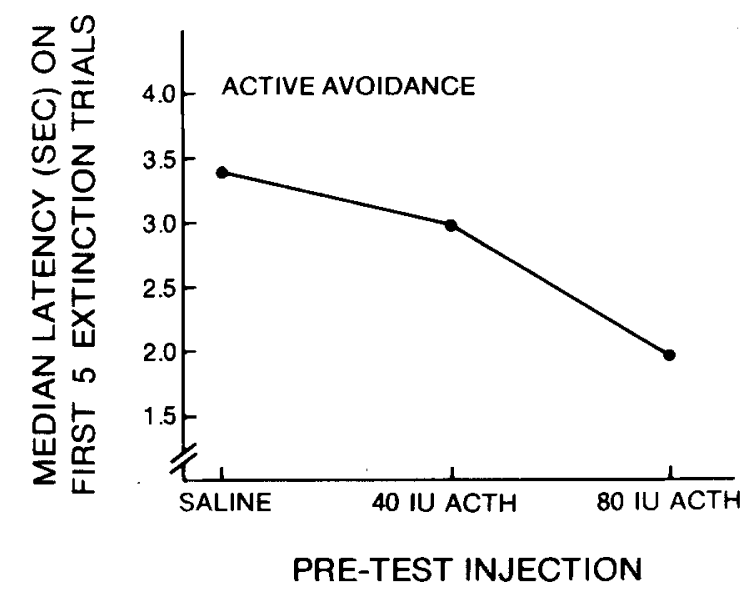

Figure 2. Median latency on first five active avoidance test trials in Experiment 1.

comparisons (with the Mann-Whitney U test) were made between subjects given ACTH or saline prior to test. With this analysis, it was found that subjects given the high dose of ACTH prior to test took significantly more trials to reach the test criterion $(\mathrm{z}=1.99, \mathrm{p}<.05$; U corrected for ties) than subjects administered saline. Furthermore, it was also found that subjects given the high dose of ACTH had significantly shorter latencies on the first five test trials than subjects given saline $(U=56, p<.05)$. No other comparisons were significant.

\section{Discussion}

As low latencies and prolonged resistance to extinction are indicative of good retention, the results of Experiment 1 suggest that pretest administration of ACTH (at least a very high dose) was effective in alleviating a performance deficit produced by extinction. However, a sim- 
pler alternative explanation for the results of Experiment 1 is possible. If ACTH merely increased the general activity of the subject, the same pattern of results could occur. Subjects that were more active would be likely to have lower latencies and require more trials to reach a criterion of not responding, irrespective of any memory processes. However, this same activity effect should impair performance in subjects administered ACTH prior to a task that involved refraining from a response, such as a passive avoidance test. If ACTH produces the recovery of the extinguished avoidance response, then subjects given pretest injections of ACTH should show enhanced performance regardless of the nature of the task used to indicate retention (i.e., active or passive avoidance). In order to determine whether the results of the first experiment were due to an artifact of activity changes induced by $\mathrm{ACTH}$, or rather to some influence of ACTH on memory, Experiment 2 , employing a passive avoidance task, was undertaken.

\section{EXPERIMENT 2}

\section{Method}

Subjects. Fifty-four adult male Albino rats (ranging from 78 to 118 days of age), purchased from the Holtzman Company, served as subjects. The subjects were experimentally naive at the beginning of this experiment. They were housed in individual wire-mesh hanging cages, given ad-lib access to food and water, and maintained on a 15-/9-h lightdark cycle.

Apparatus. A $47 \times 18.5 \times 22.7 \mathrm{~cm}$ Plexiglas chamber was used. This apparatus was divided into two equal-sized compartments, separated by a $8 \times 8 \mathrm{~cm}$ guillotine doorway. One compartment, including the lid, was painted black. The other compartment was painted white, with the exception of the lid, which was clear. A 15-W light bulb was suspended $30 \mathrm{~cm}$ above the center of the white compartment. This was the only source of illumination in the experimental room. The floor of the apparatus was constructed of .4-cm stainless steel grids spaced $1 \mathrm{~cm}$ apart. Behavior of each subject was monitored visually by means of a tilted mirror placed under the center of the apparatus.

Procedure. The subjects were assigned randomly to one of six different treatment conditions. On the 1 st day of the experiment, all subjects received Pavlovian differential fear conditioning. Fear conditioning consisted of placing the subject on the black side of the apparatus for $2 \mathrm{~min}$ and during that time administering six inescapable footshocks $(150 \mathrm{~V} / 1 \mathrm{sec}$; unscrambled) on a variable time schedule. After this 2 -min period, the subjects were placed on the white side of the apparatus for a 2 -min period, during which no shock was administered. This sequence was then repeated an additional time. Thus, training lasted $8 \mathrm{~min}$, and 12 shocks were administered during two 2 -min sessions during which the subject was confined on the black side (six shocks during each 2-min session). This procedure had proven effective in conditioning fear to the black compartment in a number of earlier studies (e.g., Ebner, Richardson, \& Riccio, 1981; Richardson, Ebner, \& Riccio, 1981; Richardson, Riccio, Jamis, Skoczen, \& Cabosky, 1982; Richardson, Riccio, \& Mowrey, 1982).

Twenty-four hours after training, all subjects received an extinction treatment designed to reduce their fear of the black compartment. Extinction consisted simply of a nonreinforced exposure to the black fear cues. Two levels of extinction were employed in this experiment in order to determine if ACTH-induced recovery of an extinguished response would be influenced by the degree to which that response had been extinguished. Thus, half the subjects received a 15-sec nonreinforced exposure to the black compartment and the other half received a 30 -sec nonreinforced exposure.

Twenty-four hours after the extinction treatment ( $48 \mathrm{~h}$ after training) subjects were tested for retention of conditioned fear. Retention testing consisted of placing the subject on the white side of the apparans facing away from the door. After $10 \mathrm{sec}$, the door separating the two compartments was opened. Latency to enter the black compartment for the first time (all four paws) and the total amount of time spent on the white (safe) side (TTW) during the 10-min test session were recorded as indices of retention. High latency and TTW scores are indicative of good retention. No shocks were administered during testing.

Shortly prior $(10-20 \mathrm{~min})$ to the retention test, the subjects were injected, subcutaneously, with $80 \mathrm{IU}$ ACTH, $40 \mathrm{IU}$ ACTH, or $1 \mathrm{ml} \mathrm{sa-}$ line. The subjects given saline served as controls for any spontaneous recovery that may have occurred overnight as well as any effects of the injection per se on the avoidance behavior.

\section{Results}

A two-way ANOVA ( 2 levels of extinction $\times 3$ types of pretest injection) on the latency data indicated a significant main effect of injection treatment $[\mathrm{F}(2,48)=$ $3.79, p<.05$ ], but no main effect of level of extinction $(F<1.0)$ and no interaction of these two variables $(F<1.0)$. These data are depicted in Figure 3. Analysis of the TTW data showed a comparable pattern of results: Significant main effect of injection treatment $[F(2,48)=4.09, p<.05]$ but no main effect of level of extinction $[F(2,48)=1.75]$ and no interaction of these two variables $(F<1.0)$.

Since the preliminary analysis demonstrated that there was no main effect of level of extinction, these groups were collapsed across type of pretest injection. For example, subjects given saline prior to test, regardless of whether they had received a $15-\mathrm{sec}$ or a $30-\mathrm{sec}$ extinction exposure, were collapsed into a single group. Pairwise comparisons on these collapsed data were then performed using Tukey's HSD test. These analyses indicated that subjects given ACTH prior to test had significantly longer latencies than subjects given saline prior to test (40 IU ACTH vs. saline, $\mathrm{p}<.05 ; 80 \mathrm{IU}$ ACTH vs saline, $\mathrm{p}<.01$ ). The same pattern of results was found in analyzing the TTW data (40 IU ACTH vs. saline, $\mathrm{p}<.05 ; 80$ IU ACTH vs. saline $\mathrm{p}<.01$ ). Subjects given ACTH prior to test (either 40 or $80 \mathrm{IU}$ ) did not differ.

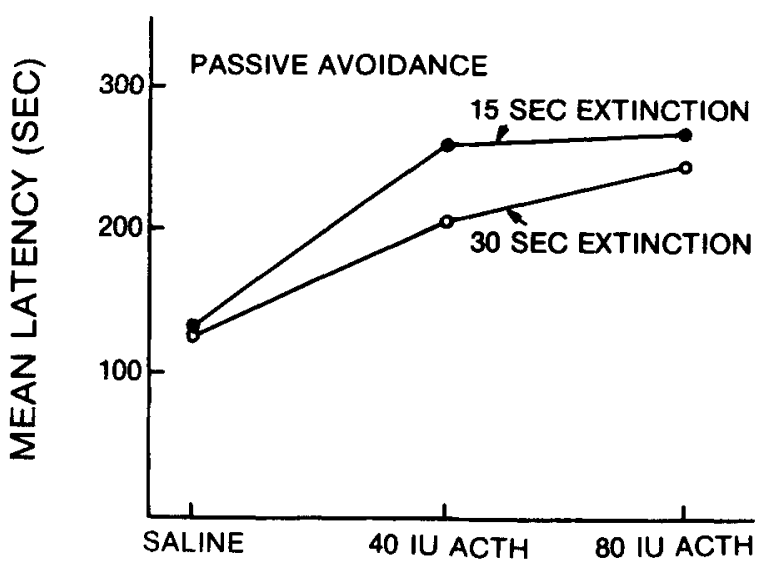

PRE-TEST INJECTION

Figure 3. Mean latency to enter the dark (fear) compartment in Experiment 2. 


\section{Discussion}

The results of the second experiment demonstrate that pretest injections of ACTH enhance retention of an extinguished fear memory measured by a passive avoidance test. Both doses of ACTH employed in this experiment were effective in producing recovery of the extinguished response. As noted earlier, one aim of the present experiment was to examine the influence of ACTH in recovering the extinguished response after two different levels of extinction. Unfortunately, the two different amounts of nonreinforced exposure to the originally established fear cues employed in this experiment $(15$ and $30 \mathrm{sec})$ did not produce different amounts of extinction, thus making it impossible to determine if there was an interaction of level of extinction and ACTH-induced recovery. Parameters different from those used in this experiment will have to be employed in order to determine if such an interaction exists.

However, the effectiveness of pretest injections of ACTH in alleviating performance deficits produced by an extinction treatment can clearly be seen in the increased passive avoidance latencies in this experiment. Because this experiment required inhibition of a response as an index of retention, whereas the first experiment required production of a response, these results cannot be due to ACTH's affecting some aspect of motor performance. A more viable interpretation of these results is that pretest injections of ACTH facilitate retrieval of the earlier acquired aversive memory-whether it is measured by a passive or an active avoidance procedure.

\section{EXPERIMENT 3}

Taken together, the results of the first two experiments demonstrate that pretest injections of ACTH can attenuate the effects of an earlier extinction treatment on retention of a fear memory. A likely explanation of these results is that exogenous administration of ACTH shortly prior to test maximizes the similarity of internal states present at training and testing. As the resemblance of training and testing sessions increases, the probability of retrieving information acquired during the training session also increases (cf. Mactutus, McCutcheon, \& Riccio, 1980; Quartermain \& Judge, 1983; Richardson, Guanowsky, Ahlers, \& Riccio, 1984; Spear, 1973, 1978). If this is, indeed, the mechanism by which the findings of the first two experiments can be best explained, then delaying the test for some period after administration of ACTH should reduce or eliminate the recovery of the extinguished memory. That is, since ACTH effects are transient, the reactivation of memory should be inversely related to the delay between hormone administration and testing. In fact, this is the pattern of results typically observed in the amnesia paradigm (Mactutus, Smith, \& Riccio, 1980; Rigter, Elbertse, \& Van Riezen, 1975) where exogenous ACTH serves to alleviate retention deficits produced by retrograde amnesia, but only when testing occurs shortly after ACTH administration (but see Keyes,
1974). The purpose of this experiment was to determine if delaying the test after hormone administration would alter the ACTH-induced recovery of an extinguished memory observed in the first two experiments.

\section{Method}

Subjects. Seventy-two adult male rats (60-157 days of age) purchased from the Holtzman Company served as subjects. All subjects were experimentally naive at the start of this experiment. Housing and handling procedures were the same as in Experiment 2.

Apparatus. The same apparatus used in Experiment 2 was employed. Procedure. All training, extinction, and testing procedures were the same as in Experiment 2. The extinction session was always $30 \mathrm{sec}$ in duration. The dose of ACTH was reduced to $20 \mathrm{IU}$ and was injected $15-20 \mathrm{~min}, 1 \mathrm{~h}$, or $24 \mathrm{~h}$ prior to test. The lengthening of the ACTH administration-test interval necessitated extending the entire experimental procedure so that animals were run for 4 days rather than 3 as in Experiment 2.

For the three groups of trained subjects given ACTH prior to the test, the following procedure was followed. Subjects were trained on Day 1, extinguished on Day 2, and tested on Day 4. One group was injected with ACTH $24 \mathrm{~h}$ prior to test (on Day 3), whereas the other two groups were given ACTH either $1 \mathrm{~h}$ prior or shortly (15-20 min) prior to test.

Two other groups of subjects were also trained on Day 1 and tested on Day 4. One group (retention control) received no additional treatments during that interval in order to provide a baseline of retention of this task over a 48 -h interval. The other group (Saline Control) was extinguished on Day 2 and given a saline injection shortly (15-20 min) prior to testing on Day 4 . These subjects were used to assess the effectiveness of the extinction manipulation and control for any spontaneous recovery of fear. All groups of trained subjects contained 11 or 12 animals.

The final two groups were given noncontingent footshocks (NCFS) in lieu of training. These subjects were exposed to the black-white shuttlebox in the same fashion as the trained subjects, with the exception that no footshocks were administered. One hour after exposure to the training apparatus, these subjects were returned to the training room (overhead fluorescent lighting on instead of the 15-W light), placed in an unpainted wood box $(21.5 \times 17.5 \times 19 \mathrm{~cm})$, and given a series of 12 inescapable footshocks (150 V/1 sec) in the same sequence as the trained subjects. On Day 2, all of these subjects were given a 30-sec "extinction" exposure to the black cues. On Day 4, seven of these subjects were injected with $20 \mathrm{IU}$ of ACTH shortly $(15-20 \mathrm{~min})$ prior to test and the remaining eight were given an equivalent amount of saline (also 15-20 min prior to test). These animals assessed any direct motor effects ACTH has on shocked, but untrained, animals in this task.

\section{Results}

As can be seen in Figure 4, pretest injections of ACTH produced recovery of the extinguished memory. Furthermore, there does not appear to be any effect of the interval between ACTH administration and testing. Statistical analysis, with Kruskal-Wallis ANOVAs and Mann-Whitney U tests, supported these conclusions.

Preliminary analysis of latency data indicated that there were no significant differences between trained animals given ACTH $24 \mathrm{~h}, 1 \mathrm{~h}$, or 15-20 min prior to test $(\mathrm{H}=$ $.63, p>.20$ ). Thus, these groups were combined into one (Group ACTH). Furthermore, as latencies in salineor ACTH-injected subjects given NCFS in lieu of training did not differ significantly $(U=58, p>.20)$, these two groups were also combined (Group NCFS).

A Kruskal-Wallis ANOVA was done to compare the latency data from the following conditions: Group ACTH, Group NCFS, saline control, and retention control. A sig- 


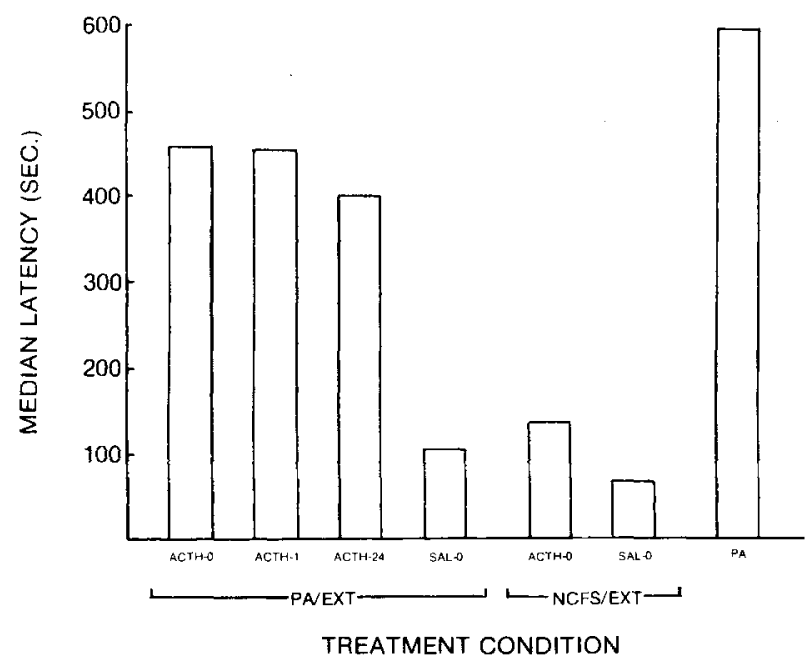

Figure 4. Median latency to enter the dark (fear) compartment in Experiment 3. PA/EXT refers to animals that received Pavlovian fear conditioning in the black compartment and were then extinguished. NCFS/EXT refers to animals given noncontingent exposure to shock, followed by nonreinforced exposure to the black compartment. The interval in hours between injection and testing is indicated by the number following the agent administered (e.g., ACTH-1 was tested $1 \mathrm{~h}$ after the hormone injection).

nificant treatment effect was obtained $(H=16.18$, $\mathrm{p}<.01$ ), and therefore, subsequent comparisons were conducted with Mann-Whitney U tests. These tests indicated that the combined group of trained subjects given ACTH prior to test had significantly longer latencies than the group of trained subjects given saline prior to test $(\mathrm{z}$ $=2.63, \mathrm{p}=.009$ ) or the combined group of nontrained subjects given ACTH or saline prior to test $(\mathrm{z}=2.38$, $\mathrm{p}=.02$ ), but were not statistically different from the retention control group $(\mathrm{z}=1.74, \mathrm{p}=.08)$. The only other significant comparisons with the latency data were that the retention control group was superior to subjects given saline prior to test $(\mathrm{U}=19, \mathrm{p}<.02)$ and to subjects given NCFS in lieu of training $(U=27, p<.02)$. The overall pattern of results was identical for the TTW data, except that the trained subjects given saline prior to test were significantly different from the nontrained subjects on this measure, $(U=43, p<.05)$.

\section{Discussion}

While these results replicate our earlier findings (Experiment 2), it was somewhat surprising that there was no effect of the interval separating ACTH administration and testing. Circulating levels of ACTH should have returned to normal $24 \mathrm{~h}$ after an exogenous administration (even with the massive dose employed here). Given these findings, it is somewhat harder to propose that pretest injections of ACTH are effective in recovering an extinguished fear memory because of an increased similarity between the training and testing sessions. The internal state of animals given ACTH $24 \mathrm{~h}$ prior to test would certainly be more like the internal state of animals given saline rather than the internal state present in subjects given ACTH shortly prior to test. Since the doses employed in these three experiments were very large, however, a final experiment was conducted to determine if the findings of Experiment 3 could be replicated with a more typically used level of ACTH (4 IU).

\section{EXPERIMENT 4}

Given that similar recovery of the originally trained response was obtained both with an active avoidance task (Experiment 1) and a passive avoidance task (Experiments 2 and 3), and that ACTH had no apparent influence on latencies of shocked but nontrained subjects (Experiment 3), it seems reasonable to conclude that even at high dose levels ACTH is not simply affecting motor performance. However, if recovery of an extinguished memory were possible with only extremely large doses of ACTH, then these findings would be of less general interest.

Thus, this experiment was a partial replication of the previous experiment but with a much smaller dose of ACTH (4 IU). This experiment had a twofold purpose: (1) to determine if the recovery of extinguished fear memories found in the first three experiments of this study was due simply to the high doses employed, and (2) to determine if ACTH produces a reliable recovery from extinction when administered as long as $24 \mathrm{~h}$ prior to testing.

\section{Method}

Subjects. Thirty-two naive adult male rats, 70-127 days of age and purchased from the Holtzman Company, served as subjects. Housing and handling conditions were the same as in Experiment 2.

Apparatus. A $38 \times 18 \times 21 \mathrm{~cm}$ Plexiglas chamber, divided into two equal-sized compartments, was used as the training and testing apparatus. One compartment, including the lid, was painted black. The other compartment was painted white and had a clear Plexiglas lid. A $15-W$ light bulb was suspended $30 \mathrm{~cm}$ over the center of the white compartment. A black Plexiglas restrainer $(16.5 \times 15.3 \times 9.5 \mathrm{~cm})$ was in place on the black side at all times. A guillotine doorway $(8 \times 8 \mathrm{~cm})$ connected the two compartments. The floor consisted of $.2-\mathrm{cm}$ stainless steel grids spaced $1 \mathrm{~cm}$ apart. A matched impedance shock source (Campbell \& Teghtsoonian, 1958) was connected to the grids of the black side to which a scrambled footshock $(150 \mathrm{~V} / 1 \mathrm{sec})$ could be delivered. Behavior of each subject was monitored visually by means of a tilted mirror placed under the center of the apparatus. White noise in the experimental room masked any extraneous sounds.

Procedures. All training and testing procedures were the same as those employed in Experiment 3. Extinction consisted of a nonreinforced exposure to the black fear compartment, but in this experiment the duration of the extinction session was increased to $90 \mathrm{sec}$. Three groups of subjects were trained on Day 1 and extinguished on Day 2. Two of these groups were injected either with 4 IU of ACTH or an equivalent volume of saline, shortly prior (15-20 min) to testing on Day 4 . The third group that had been trained and extinguished was given 4 IU of ACTH $24 \mathrm{~h}$ prior (on Day 3) to test. A final group of subjects was trained on Day 1 and tested on Day 4. These subjects assessed the level of retention that could be expected when using the present parameters.

\section{Results}

A Kruskal-Wallis ANOVA on the latency data indicated a significant effect of treatment $(H=14.57, \mathrm{p}<.01)$. Subsequent comparisons showed that subjects given saline prior to test had significantly shorter latencies than 


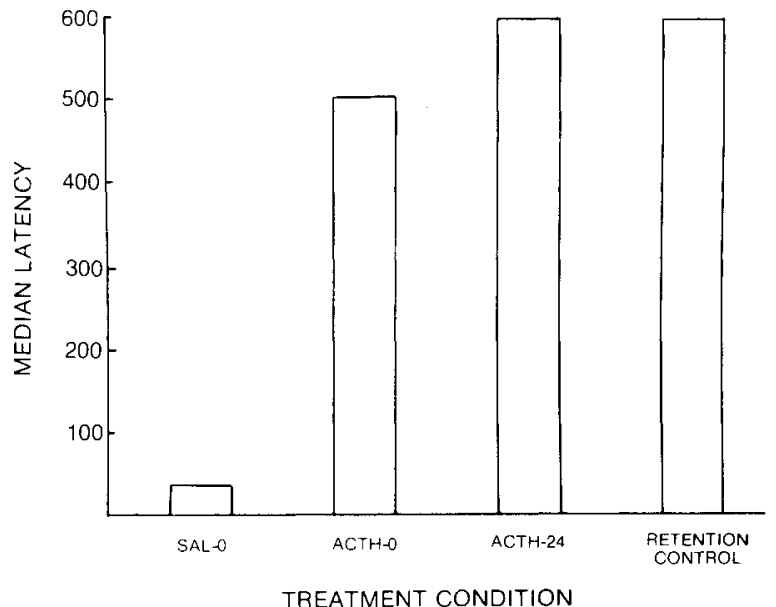

Figure 5. Median latency to enter the dark (fear) compartment in Experiment 4.

subjects given ACTH shortly prior to test $(\mathrm{U}=6$, $\mathrm{p}<.002)$, АCTH $24 \mathrm{~h}$ prior to test $(\mathrm{U}=9, \mathrm{p}=.02)$, as well as the unextinguished retention controls $(U=0$, $\mathrm{p}<.002$ ). The latter three groups did not differ. These results are depicted in Figure 5. The identical pattern of results was found in the analysis of the TTW data.

\section{Discussion}

The present data demonstrating ACTH-induced recovery of fear-motivated behavior following extinction indicate that the results of the first three experiments of this study were not due to the large doses employed. Furthermore, this experiment replicates the unexpected finding of Experiment 3 in that ACTH injections given even $24 \mathrm{~h}$ prior to test were again found to be effective in producing recovery of an extinguished fear response.

\section{GENERAL DISCUSSION}

This series of experiments demonstrates that exogenously administered ACTH can produce the recovery of an extinguished fear response. Thus, the findings extend previous research showing ACTH-induced recovery from performance deficits produced by quite different experimental manipulations, for example, retrograde amnesia (Mactutus, Smith, \& Riccio, 1980) and infantile amnesia (Haroutunian \& Riccio, 1979).

The effect of ACTH on previously extinguished learned responding cannot be attributed to direct influences of the peptide on motor behavior for three reasons. First, in Experiment 1 an active avoidance task was used to assess hormone effects, whereas in the remaining three experiments a passive avoidance task was employed. If the results of the first experiment were simply due to exogenous ACTH's activating animals, then one would have expected that ACTH prior to a passive avoidance test would also result in short latencies and therefore poor performance, rather than the long latencies that were ob- tained. Further evidence against the notion that ACTH is merely altering motor performance can be found in Experiment 3, which demonstrated that pretest injections of ACTH had no effect on test scores of shocked, but untrained, subjects. From this, one can infer that pretest injections of ACTH can alter performance, but only if the subject has earlier received fear conditioning to the test cues. A third piece of evidence that ACTH is not simply altering motor performance is the durability of recovery found in Experiments 3 and 4. The direct influence of ACTH on motor performance should have subsided $24 \mathrm{~h}$ after administration, yet it was found in the final two experiments that ACTH-induced recovery of an extinguished fear memory persisted for at least $24 \mathrm{~h}$. (As will be discussed momentarily, this persistence of recovery can be seen as problematic for memory interpretations of this phenomenon also.)

One other potential interpretation of the present results which does not invoke memory-related mechanisms can be suggested. In traditional studies on extinction, presentation of a novel stimulus has been found to cause "disinhibition," that is, return or recovery of the conditioned response (Pavlov, 1927, pp. 61-66; cf. Brimer, 1970), and perhaps that is what occurred in the experiments reported here. Administration of ACTH might be a sufficiently novel stimulus condition to produce disinhibition. Such an interpretation could not easily explain the persistence of recovery over $24 \mathrm{~h}$ (Experiments 3 and 4), since the disinhibiting effect is typically observed when novel stimuli are presented along with (or in close temporal proximity to) the conditioned stimulus. Also, a recently completed study in our laboratory has replicated the ACTH-induced recovery of extinction in passive avoidance, but has shown that the phenomenon is blocked by administration of Dexamethasone prior to training (Ahlers \& Richardson, 1984). Apparently, the presence of this artificial glucocorticoid suppresses ACTH release (through the negative feedback system) during fear conditioning; subsequent administration of $\mathrm{ACTH}$ at testing then fails to provide the appropriate cues for the recovery. In addition to suggesting a relatively specific influence of ACTH on memory, the outcome argues that the ACTH state is not simply acting as a novel stimulus to disinhibit an extinguished response.

As mentioned earlier, our general rationale for these experiments was that increasing the similarity or congruence of internal states at training and testing would alleviate the effects of extinction. Administration of ACTH shortly prior to the test should increase the similarity of the internal milieu to that at training and thus lead to better retrieval (Spear, 1973, 1978). The results of Experiments 1 and 2 are consistent with this view. However, the lack of an effect in delaying the test after ACTH administration found in Experiments 3 and 4 is more puzzling. Introducing a long interval between administration of ACTH and testing was expected to reduce the recovery of extinguished performance. Presumably, the similarity of internal states at testing and training is not signifi- 
cantly increased for those subjects experiencing a delay between ACTH administration and test. As the results of the final two experiments in this study demonstrated that ACTH was effective in recovering an extinguished fear memory even $24 \mathrm{~h}$ after administration, some process other than, or in addition to, increasing the correspondence of internal states at training and testing must be involved.

In this connection, it should be noted that a wide variety of treatments have been employed to alleviate the performance impairments associated with a number of experimental manipulations (i.e., experimentally induced amnesia, long retention intervals, infantile amnesia, extinction), and in many of these experiments the recovery of memory outlasts the direct influences of the reactivation treatment. For example, exposure to a noncontingent footshock (NCFS) has been demonstrated to be effective in producing recovery of memory in experiments on experimentally induced amnesia (Miller \& Springer, 1972), extinction (Rescorla \& Heth, 1975), and infantile amnesia (Richardson et al., 1981). In each of these studies, memory recovery was evident at least $24 \mathrm{~h}$ after administration of NCFS. An even more pertinent example of persistent recovery of memory is seen in work with amphetamine. Braun, Meyer, and Meyer (1966) showed that this drug reversed the loss of brightness discrimination incurred by posterior decortication in rats. Recovery persisted even with a long delay between amphetamine administration and testing. Furthermore, Judge and Quartermain (as described in Quartermain \& Judge, 1983) found that forgetting produced by a long retention interval could be alleviated by pretest injections of amphetamine and that pretest injections of amphetamine were effective in reducing longterm retention deficits even when given $24 \mathrm{~h}$ prior to test. Quartermain and Judge (1983) suggested that the amphetamine injection reactivated the earlier established memory and caused further processing of that memory (cf. Ebner, Tisdale, \& Riccio, 1978; Spear, Hamberg, \& Bryan, 1980). Perhaps ACTH is working in a similar fashion in the current experiments. Rather than only increasing retrievability of the earlier established fear memory shortly after administration of ACTH, perhaps this treatment causes the memory to be reactivated and processed further. Thus, the accessability of the extinguished memory is enhanced even at times long after ACTH administration.

\section{REFERENCES}

Ahlers, S. A., \& Richardson, R. (1984). Pretreatment with dexamethasone blocks ACTH-induced recoverey of an extinguished avoidance response. Manuscript submitted for publication.

BoHUS, B., \& DEWIED, D. (1966). Inhibitory and facilitory effect of two related peptides on extinction of avoidance behavior. Science, 153, 318-320.

BoHUs, B., \& DEWIED, D. (1981). Actions of ACTH- and MSH-like peptides on learning, performance and retention. In J. L. Martinez, Jr., R. A. Jensen, R. B. Messing, H. Rigter, \& J. L. McGaugh (Eds.), Endogenous peptides and learning and memory processes (pp. 5977). New York: Academic Press.
Braun, J. J., Meyer, P. M., \& Meyer, D. R. (1966). Sparing of a brightness habit in rats following visual decortication. Journal of Comparative and Physiological Psychology, 61, 79-82.

BRIMER, C. J. (1970). Disinhibition of an operant response. Learning and Motivation, 1, 346-371.

CAMPBell, B. A., \& Teghtsoontan, R. (1958). Electrical and behavioral effects of different types of shock stimuli on the rat. Journal of Comparative and Physiological Psychology, 51, 185-192.

DEWIED, D. (1966). Inhibitory effects of ACTH and related peptides on extinction of conditioned avoidance behavior in rats. Proceedings of the Society for Experimental Biology and Medicine, 122, 28-32.

EBNER, D. L., RichaRDSON, R., \& Riccio, D. C. (1981). Ovarian hormones and retention of learned fear in rats. Behavioral and Neural Biology, 33, 45-58.

EbNeR, D. L., Tisdale, M., \& Riccio, D. C. (1978). Does reinstatement strengthen memory disproportionately? Paper presented at the International Society for Developmental Psychobiology.

ESTES, W. K. (1955). Statistical theory of spontaneous recovery and regression. Psychological Review, 62, 145-154.

Haroutunian, V., \& Riccio, D. C. (1979). Drug-induced "arousal" and the effectiveness of CS exposure in the reinstatement of memory. Behavioral and Neural Biology, 26, 115-120.

KAMIN, L. J. (1968). "Attention-like" processes in classical conditioning. In M. R. Jones (Ed.), Miami Symposium on the Prediction of Behavior: Aversive Stimulation (pp. 9-31). Miami: University of Miami Press.

Kamin, L. J. (1969), Predictability, surprise, attention, and conditioning. In B. A. Campbell \& R. M. Church (Eds.), Punishment and aversive behavior. New York: Appleton-Century-Crofts.

KeYES, J. B. (1974). Effect of ACTH on ECS produced amnesia of a passive avoidance task. Physiological Psychology, 2, 307-309.

KLEIN, S. B. (1972). Adrenal-pituitary influence in reactivation of avoidance-memory in the rat after intermediate intervals. Journal of Comparative and Physiological Psychology, 79, 341-359.

KLEIN, S. B., SPEAR, N. E. (1970). Forgetting by the rat after intermediate intervals ("Kamin effect") as retrieval failure. Journal of Comparative and Physiological Psychology, 71, 165-170.

Mactutus, C. F., FereK, J. M., \& Riccio, D. C. (1980). Amnesia induced by hyperthermia: An unusually profound, yet reversible, memory loss. Behavioral and Neural Biology, 30, 260-277.

Mactutus, C. F., McCutcheon, K., \& Riccio, D. C. (1980). Body temperature cues as contextual stimuli: Modulation of hypothermiainduced retrograde amnesia. Physiology \& Behavior, 25, 875-883.

Macturus, C. F., Smith, R. L., \& Riccro, D. C. (1980). Extending the duration of ACTH-induced memory reactivation in an amnestic paradigm. Physiology \& Behavior, 24, 541-546.

MiLLER, R. R., \& SPRINGER, A. D. (1972). Induced recovery of memory in rats following electroconvulsive shock. Physiology \& Behavior, 8, 645-651.

Pavlov, I. P. (1927). Conditioned reflexes. (T. V. Anrep, Trans.). London: Oxford University Press.

Quartermain, D., \& JUDGE, M. E. (1983). Retrieval enhancement in mice by pretest amphetamine injection after a long retention interval. Physiological Psychology, 11, 166-172.

Rescorla, R. A., HeTH, C. E. (1975). Reinstatement of fear to an extinguished conditioned stimulus. Journal of Experimental Psychology: Animal Behavior Processes, 104, 88-96.

Richardson, R., Ebner, D. L., \&iccio, D. C. (1981). Effects of delayed testing on passive avoidance of conditioned fear stimuli in young rats. Bulletin of the Psychonorhic Society, 18, 211-214.

Richardson, R., Guanowsky, V., Ahlers, S. T., Riccio, D. C. (1984). Role of body temperature in the onset of, and recovery from, hypothermia-induced anterograde amnesia. Physiological Psychology, 12, $125-132$.

Richardson, R., Riccio, D. C., Jamis, M., Skoczen, T., ¿ Cabosky, J. (1982). Modification of reactivated memory through "counterconditioning. American Journal of Psychology, 95, 67-84.

Richardson, R., Riccio, D. C., \& Mowrey, H. (1982). Retrograde amnesia for previously acquired Pavlovian conditioning: UCS exposure as a reactivation treatment. Physiological Psychology, 10, 384-390. RigTer, H., ElberTSE, R., \& VAN RIEZEN, H. (1975). Time-dependent 
anti-amnesic effect of $\mathrm{ACTH}_{4-10}$ and desglycinamide-lysine vasopressin. Progress in Brain Research, 42, 163-171.

Rigter, H., VAN RIEzen, H., \& DEWIED, D. (1974). The effects of $\mathrm{ACTH}$ - and vasopressin-analogues on $\mathrm{CO}_{2}$-induced retrograde amnesia in rats. Physiology \& Behavior, 13, 381-388.

SPEAR, N. E. (1973). Retrieval of memory in animals. Psychological Review, 80, 163-175.

SPEAR, N. E. (1978). Processing of memories: Forgetting and retention. Hillsdale, NJ: Erlbaum.
Spear, N. E., Hamberg, J. M., \& Bryan, R. (1980). Forgetting ol recently acquired or recently reactivated memories. Learning and Mati: vation, 11, 456-475.

\section{NOTE}

1. It is realized that these doses are much higher than typically used Due to a procedural error, the doses in the first three experiments were 5 times that intended. This error was rectified in Experiment 4.

(Manuscript received June 19, 1984;

accepted for publication August 24, 1984.) 